\title{
Research Square \\ NFKBIA has the Capacity to Serve as a Diagnostic Biomarker for Prostate Cancer Patient
}

\section{Hao Zi}

Huaihe Hospital of Henan University

Wen-Lin Tao

Huaihe Hospital of Henan University

Lei Gao

Huaihe Hospital of Henan University

\section{Zhao-Hua Yu}

Huaihe Hospital of Henan University

\section{Xiao-Dong Bai}

Huaihe Hospital of Henan University

Xiao-Dong Li ( $\nabla$ fcgm6h@yeah.net )

Huaihe Hospital of Henan University https://orcid.org/0000-0003-2378-0153

\section{Primary research}

Keywords: NFKBIA, NF-kB, Prostate cancer, Diagnosis

Posted Date: August 11th, 2020

DOl: https://doi.org/10.21203/rs.3.rs-54669/v1

License: (c) (i) This work is licensed under a Creative Commons Attribution 4.0 International License. Read Full License 


\section{Abstract}

Background: Prostate cancer is the the second leading cause of cancer-related death in male. NF-KB inhibitor alpha gene (NFKBIA), is found dys-expressed in the progression of tumors. The aim of this study was to investigate the expression of $N F K B I A$ and its diagnostic value in prostate cancer patients.

Methods: The mRNA expression of NFKBIA was detected with quantitative real-time polymerase chain reaction (qRT-PCR) assay and the association of its expression with clinical characteristic was analyzed via Chi-square test. Receiver operating characteristic (ROC) curve was built to evaluate the diagnostic value of serum NFKBIA.

Results: The mRNA expression level of NFKBIA was significantly increased in prostate cancer patients compared with healthy controls $(P<0.01)$. The high expression of $N F K B I A$ was significantly associated with pathological T stage $(P=0.010)$ and differentiation $(P=0.019)$. ROC curve showed that serum NFKBIA had a high diagnostic value in differentiating prostate cancer patients from healthy individuals. The area under the ROC curve (AUC) value was 0.873 corresponding with a sensitivity of $85.6 \%$ and a specificity of $78.3 \%$.

Conclusions: The expression of $N F K B I A$ was up-regulated in serum of prostate cancer patients and it may be a useful diagnostic bio-maker for the early detection of this cancer.

\section{Background}

Prostate cancer is the most commonly diagnosed male malignancy worldwide and the second most common cause of cancer-related deaths in the United States [1,2]. The clinical behavior of prostate tumors varies from low-grade indolent tumors to aggressive tumors that is highly malignant with rapid invasion and early bone metastasis [1,3]. The carcinogenesis and mechanism influencing the progression and prognosis of prostate cancer is a multistep process and the incidence of the disease is continuously rising. Circulating prostate-specific antigen (PSA) is currently the most common noninvasive biomarker used for the detection of prostate cancer $[4,5]$. However, to date, there are no reliable and high specificity predictors for prostate cancer detection. Therefore, the novel cancer-related genes that may serve as reliable bio-maker should be established for the prostate cancer early detection.

Nuclear factor of $\kappa B(N F-\kappa B)$, a kind of important nuclear transcription factor, can regulate cell proliferation, apoptosis, malignant transformation, invision and metastasis [6]. Aberrant expression of $N F-K B$ is reported to be involved in cancer initiation and progression [7]. In current studies, aberrant activation of $N F-K B$ was found in glioblastomas and considered a tumor suppressor gene $[8,9]$. Moreover, $N F-K B$ is present in an inactive form when it is bound to $\mathrm{I} \kappa B a$, which is encoded by $N F-K B$ inhibitor alpha gene (NFKBIA) [10]. It has been indicated that NFKBIA has identified to be involved in carcinogenesis and dysregulated in a variety of cancers, such as head and neck squamous cell carcinoma and glioma [11, 12]. However, few studies had been investigated the diagnostic performance of NFKBIA in prostate cancer. 
In the present study, we investigated the expression level of NFKBIA in prostate cancer samples and healthy control samples. The relationship between NFKBIA expression and clinicopathological characteristics of prostate cancer patients was analyzed. Moreover, we also investigate the diagnostic value of NFKBIA in prostate cancer.

\section{Methods}

\section{Patients and specimens}

In the present study, blood samples were obtained from 132 patients with prostate cancer and 120 healthy controls during their hospitalization and physical examination between Huaihe Hospital of Henan University. $10 \mathrm{ml}$ whole blood was collected from each participant and serum was separated by centrifugation at $12,000 \mathrm{~g}$ for $10 \mathrm{~min}$ at $4^{\circ} \mathrm{C}$. Then the samples were stored at $-80^{\circ} \mathrm{C}$ until RNA extraction. The clinicopathological data were obtained from all cancer patients and listed in Table 1. 
Table 1

Association of NFKBIA expression with clinicopathological features of prostate cancer patients

\begin{tabular}{|c|c|c|c|c|c|}
\hline \multirow[t]{2}{*}{ Parameters } & \multirow[t]{2}{*}{ Cases $(n=132)$} & \multicolumn{2}{|c|}{ NFKBIA expression } & \multirow{2}{*}{$x^{2}$} & \multirow[t]{2}{*}{$P$} \\
\hline & & $\operatorname{Low}(n=51)$ & High $(n=81)$ & & \\
\hline Age & & & & 0.328 & 0.567 \\
\hline$<60$ & 74 & 27 & 47 & & \\
\hline$\geq 60$ & 58 & 24 & 34 & & \\
\hline Tumor size & & & & 0.005 & 0.941 \\
\hline$<2 \mathrm{~cm}$ & 73 & 28 & 45 & & \\
\hline$\geq 2 \mathrm{~cm}$ & 59 & 23 & 36 & & \\
\hline Preoperative PSA & & & & 2.108 & 0.147 \\
\hline$<10 \mathrm{ng} / \mathrm{mL}$ & 75 & 33 & 42 & & \\
\hline$\geq 10 \mathrm{ng} / \mathrm{mL}$ & 57 & 18 & 39 & & \\
\hline Pathological T stage & & & & 6.647 & 0.010 \\
\hline $\mathrm{T} 1-\mathrm{T} 2$ & 72 & 35 & 37 & & \\
\hline T3-T4 & 60 & 16 & 44 & & \\
\hline Metastasis & & & & 2.375 & 0.123 \\
\hline negative & 77 & 34 & 43 & & \\
\hline positive & 55 & 17 & 38 & & \\
\hline Differentiation & & & & 5.546 & 0.019 \\
\hline poor & 71 & 34 & 37 & & \\
\hline Moderate + well & 61 & 17 & 44 & & \\
\hline
\end{tabular}

The study was approved by the Research Ethics Committee of Huaihe Hospital of Henan University. And all participants signed written informed consents prior to sampling.

\section{RNA extraction and quantitative real-time PCR (qRT-PCR)}

Total RNA was extracted with from serum samples with TRIzol reagent (Invitrogen, Carlsbad, CA, USA) and dissolved in $10 \mathrm{ml}$ diethypyrocarbonate-treated water. And reverse transcriptions were performed using the Reverse Transcription System (Promega, WI, USA) according to the manufacturer's instructions. QRT-PCR analysis was performed with ABI 7900 real-time PCR system (Applied Biosystems, CA, USA) according to the manufacturer's protocol. The relative expression of NFKBIA was determined by the 
comparative $2^{\Delta \Delta C t}$ (threshold) method and $\beta$-actin was used as endogenous control. Each sample was repeated in triplicate.

\section{Statistical analysis}

All statistical analyses were carried out using the software of SPSS 21.0 and GraphPad Prism 5. The difference between two groups was analyzed by student's $t$ test. The $\chi^{2}$ test was used to analyze the relationship between NFKBIA expression and the clinicopathological characteristics of patients. The receiver operating characteristic $(\mathrm{ROC})$ curve was plotted to distinguish prostate patients from healthy individuals. The diagnostic potential of serum NFKBIA was evaluated by calculating the area under ROC curve (AUC), sensitivity and specificity. $P$ values less than 0.05 were considered to be statistically significant.

\section{Results}

\section{The expression of NFKBIA was increased in prostate cancer patients}

The mRNA expression level of NFKBIA in 132 prostate cancer patients and 120 healthy volunteers were detected via qRT-PCR. As shown in Figure 1, the relative mRNA expression of NFKBIA was significantly higher in prostate cancer samples than that in healthy controls $(P<0.01)$.

\section{Relationship between NFKBIA expression and clinicopathological characteristics of prostate cancer patients}

To investigate whether NFKBIA was involved in the development of prostate cancer, the association between NFKBIA expression and clinicopathological characteristics was analyzed. As shown in Table 1, the expression of NFKBIA was found to be significantly associated with pathological T stage $(P=0.010)$ and differentiation $(P=0.019)$. However, there was no significant association between NFKBIA expression and other clinical parameters including age, tumor size, preoperative PSA and metastasis (all, $P>0.05$ ).

\section{Diagnostic value of $N F K B I A$ in prostate cancer}

ROC curve analysis was performed to investigate the correlations between NFKBIA dysregulation and diagnosis in prostate cancer patients. As shown in Figure 2, NFKBIA had a relatively high accuracy in differentiating prostate cancer patients from healthy individuals, with an AUC value of $0.873(95 \% \mathrm{Cl}$ : $0.829-0.917$ ), a sensitivity of $85.6 \%$ and a specificity of $78.3 \%$. Moreover, the cut-off value was 1.685 .

\section{Discussion}

Prostate cancer is the most common malignant tumor that presents in the prostatic tissues of the males and is the result of disordered growth of prostatic vesicle cells. Besides, it includes several phenotypes, from indolent to highly aggressive phenotypes $[2,13]$. Up to now, most prostate cancer patients were diagnosed in advanced stages and it is still a fatal disease [14]. Although a mass of efforts was made to 
improve the treatment of prostate cancer, the mortality remain high in the world. Therefore, it's crucial to find effective bio-markers for prostate cancer detection.

In the recent decades, several molecular markers have been investigated in prostate cancer as predictive biomarkers. For example, Lynch SM et al. investigated the expression of miR-200c and miR-141 and their elevated expression may have potential as a novel biomarker or therapeutic intervention in the diagnosis and prognosis of prostate cancer [15]. Pan et al. detected SPINK1 and ERG expression in initially diagnosed bone metastatic prostate cancer and found the over-expression of SPINK1 was related to poor PSA response as well as be a useful prognostic for bone metastatic prostate cancer at the time of diagnosis [16]. Fu et al. investigated both the mRNA and protein expression of $B U B 1 B$ in prostate cancer cell lines and indicated that high expression of $B U B 1 B$ was an independent predictor biomarker for the diagnosis and prognosis of prostate cancer [17]. Li et al. investigated the overexpression and significance of ribosomal L1 domain containing 1 (RSL1D1) in prostate cancer and demonstrated that it may aid in the improvement of diagnosis, prognosis and risk stratification of patients with prostate cancer [18]. Lynch SM et al. provide evidence that miR-24 has a tumor suppressor role in prostate cancer and may be a useful progression biomarker for prostate cancer [19].

$N F-K B$ has been shown to play a critical role in many physiological processes including inflammation, apoptosis, and angiogenesis as well as tumor progression [20-24]. Improper activation of NF-KB can cause enhanced cell proliferation and evasion of apoptosis, which are the cancer hallmarks. Therefore, under normal conditions, $N F-K B$ is bound to $I K B a$ inhibitor when its expression is not need. $I K B a$ is encoded by NFKBIA gene, which is also found abnormal expression involved in human cancer progression. Ata Miyar et al. found that NFKBIA expression was decreased in patients with high grad glioma, and the the low expression of NFKBIA is significantly related with poor overall survival of glioma patients [12]. Shi et al. investigated the mechanism by which HINT1 promotes the stability of inhibitor of $N F-K B a(I K B a)$ in the cytoplasm of hepatocellular carcinoma (HCC) cells and provided new evidence that HINT1 is a regulator of $I K B a$ through SCF ( $\beta$-TrCP) E3 ligase [25]. In addition, Carter SL et al. implicated that NFKBIA is an androgen regulated gene and the protein encoded by this gene, $I K B a$ is best known as an inhibitor of $N F-K B$ signaling. Moreover, $I_{K} B a$ as a key mediator of the apoptotic action induced by combination of bicalutamide and vorinostat and a promising new therapeutic target for prostate cancer [26].

In this study, we investigated the expression level of NFKBIA via qRT-PCR analysis. The result proved that the expression of NFKBIA was increased compared with healthy control. And the higher expression of $N F K B I A$ was tightly correlated with pathological T stage and differentiation, which indicated that $N F K B I A$ participated in the development and progression of prostate cancer. The ROC curve analysis showed the high AUC, sensitivity and specificity of NFKBIA expression, which revealed NFKBIA may have diagnosis value for prostate cancer detection.

\section{Conclusions}


In conclusion, NFKBIA is overexpressed in prostate cancer samples than healthy control and correlated with clinical factors. NFKBIA may be a potential diagnostic marker of prostate cancer. What's more, further studies are needed to warrant its diagnostic utility in this malignancy.

\section{List Of Abbreviations}

$N F-K B$ inhibitor alpha gene $(N F K B I A)$

quantitative real-time polymerase chain reaction (qRT-PCR)

area under the ROC curve (AUC)

prostate-specific antigen (PSA)

receiver operating characteristic $(\mathrm{ROC})$

ribosomal L1 domain containing 1 (RSL 1D1)

$N F-K B a(/ K B a)$

hepatocellular carcinoma (HCC)

IKBa through SCF ( $\beta$-TrCP)

\section{Declarations}

\section{Ethics approval and consent to participate}

This study was supported by the Ethics Committee of Huaihe Hospital of Henan University and also has been carried out in accordance with the World Medical Association Declaration of Helsinki.

The subjects had been informed the objective. Certainly, written consents were signed by every subject in this study.

\section{Consent for publication}

We obtaining permission from participants to publish their data.

\section{Availability of data and materials}

The datasets used and/or analysed during the current study are available from the corresponding author on reasonable request.

\section{Competing interests}

The authors declare that they have no competing interests. 


\section{Funding}

Not applicable.

\section{Authors' contributions}

H.Z., W.T. design of the work; L.G. the acquisition, analysis, Z.Y. interpretation of data; X.B. the creation of new software used in the work; X.L. have drafted the work or substantively revised it. All authors read and approved the final manuscript.

\section{Acknowledgements}

Not applicable.

\section{References}

1. Johnson LM, Choyke PL, Figg WD, Turkbey B: The role of MRI in prostate cancer active surveillance. BioMed research international 2014, 2014:203906.

2. Siegel RL, Miller KD, Jemal A: Cancer statistics, 2015. CA: a cancer journal for clinicians 2015, 65(1):5-29.

3. Lange PH, Vessella RL: Mechanisms, hypotheses and questions regarding prostate cancer micrometastases to bone. Cancer metastasis reviews 1998, 17(4):331-336.

4. Wolters T, van der Kwast TH, Vissers CJ, Bangma CH, Roobol M, Schroder FH, van Leenders GJ: False-negative prostate needle biopsies: frequency, histopathologic features, and follow-up. The American journal of surgical pathology 2010, 34(1):35-43.

5. Hoogland AM, Kweldam CF, van Leenders GJ: Prognostic histopathological and molecular markers on prostate cancer needle-biopsies: a review. BioMed research internationa/ 2014, 2014:341324.

6. Sung B, Pandey MK, Aggarwal BB: Fisetin, an inhibitor of cyclin-dependent kinase 6, down-regulates nuclear factor-kappaB-regulated cell proliferation, antiapoptotic and metastatic gene products through the suppression of TAK-1 and receptor-interacting protein-regulated IkappaBalpha kinase activation. Molecular pharmacology 2007, 71(6):1703-1714.

7. Kawiak A, Domachowska A: Plumbagin Suppresses the Invasion of HER2-Overexpressing Breast Cancer Cells through Inhibition of IKKalpha-Mediated NF-kappaB Activation. PloS one 2016, 11(10):e0164064.

8. Nagai S, Washiyama K, Kurimoto M, Takaku A, Endo S, Kumanishi T: Aberrant nuclear factor-kappaB activity and its participation in the growth of human malignant astrocytoma. Journal of neurosurgery 2002, 96(5):909-917.

9. Tsunoda K, Kitange G, Anda T, Shabani HK, Kaminogo M, Shibata S, Nagata I: Expression of the constitutively activated RelA/NF-kappaB in human astrocytic tumors and the in vitro implication in 
the regulation of urokinase-type plasminogen activator, migration, and invasion. Brain tumor pathology 2005, 22(2):79-87.

10. Heimberg H, Heremans Y, Jobin C, Leemans R, Cardozo AK, Darville M, Eizirik DL: Inhibition of cytokine-induced NF-kappaB activation by adenovirus-mediated expression of a NF-kappaB superrepressor prevents beta-cell apoptosis. Diabetes 2001, 50(10):2219-2224.

11. Gupta A, Kumar R, Sahu V, Agnihotri V, Singh AP, Bhasker S, Dey S: NFkappaB-p50 as a blood based protein marker for early diagnosis and prognosis of head and neck squamous cell carcinoma.

Biochemical and biophysical research communications 2015, 467(2):248-253.

12. Miyar A, Habibi I, Ebrahimi A, Mansourpour D, Mokarizadeh A, Rajabi A, Farshgar R, Eshaghzadeh M, Zamani-Ahmadmahmudi M, Nodushan SM: Predictive and prognostic value of TLR9 and NFKBIA gene expression as potential biomarkers for human glioma diagnosis. Journal of the neurological sciences 2016, 368:314-317.

13. Bertoli G, Cava C, Castiglioni I: MicroRNAs as Biomarkers for Diagnosis, Prognosis and Theranostics in Prostate Cancer. International journal of molecular sciences 2016, 17(3):421.

14. Xu W, Zhou M: A concise update on prostate pathology. Ceskoslovenska patologie 2014, 50(4):120128.

15. Lynch SM, O'Neill KM, McKenna MM, Walsh CP, McKenna DJ: Regulation of miR-200c and miR-141 by Methylation in Prostate Cancer. The Prostate 2016, 76(13):1146-1159.

16. Pan X, Zhang X, Gong J, Tan J, Yin X, Tang Q, Shu K, Shen P, Zeng H, Chen N: The expression profile and prognostic value of SPINK1 in initially diagnosed bone metastatic prostate cancer. The Prostate 2016, 76(9):823-833.

17. Fu X, Chen G, Cai ZD, Wang C, Liu ZZ, Lin ZY, Wu YD, Liang YX, Han ZD, Liu JC et al: Overexpression of BUB1B contributes to progression of prostate cancer and predicts poor outcome in patients with prostate cancer. OncoTargets and therapy 2016, 9:2211-2220.

18. Li XP, Jiao JU, Lu LI, Zou Q, Zhu S, Zhang Y: Overexpression of ribosomal L1 domain containing 1 is associated with an aggressive phenotype and a poor prognosis in patients with prostate cancer. Oncology letters 2016, 11(4):2839-2844.

19. Lynch SM, McKenna MM, Walsh CP, McKenna DJ: miR-24 regulates CDKN1B/p27 expression in prostate cancer. The Prostate 2016, 76(7):637-648.

20. Ma J, Mi C, Wang KS, Lee JJ, Jin X: 4',6-Dihydroxy-4-methoxyisoaurone inhibits TNF-alpha-induced NF-kappaB activation and expressions of NF-kappaB-regulated target gene products. Journal of pharmacological sciences 2016, 130(2):43-50.

21. Kwon HJ, Choi GE, Ryu S, Kwon SJ, Kim SC, Booth C, Nichols KE, Kim HS: Stepwise phosphorylation of p65 promotes NF-kappaB activation and NK cell responses during target cell recognition. Nature communications 2016, 7:11686.

22. Wu L, Zhang X, Zhang B, Shi H, Yuan X, Sun Y, Pan Z, Qian H, Xu W: Exosomes derived from gastric cancer cells activate NF-kappaB pathway in macrophages to promote cancer progression. Tumour 
biology : the journal of the International Society for Oncodevelopmental Biology and Medicine 2016, 37(9):12169-12180.

23. Gong J, Munoz AR, Pingali S, Payton-Stewart F, Chan DE, Freeman JW, Ghosh R, Kumar AP: Downregulation of STAT3/NF-kappaB potentiates gemcitabine activity in pancreatic cancer cells. Molecular carcinogenesis 2016.

24. Zhang Y, Lapidus RG, Liu P, Choi EY, Adediran S, Hussain A, Wang X, Liu X, Dan HC: Targeting IkappaB Kinase beta/NF-kappaB Signaling in Human Prostate Cancer by a Novel IkappaB Kinase beta Inhibitor CmpdA. Molecular cancer therapeutics 2016, 15(7):1504-1514.

25. Shi Z, Wu X, Ke Y, Wang L: Hint1 Up-Regulates IkappaBalpha by Targeting the beta-TrCP Subunit of SCF E3 Ligase in Human Hepatocellular Carcinoma Cells. Digestive diseases and sciences 2016, 61(3):785-794.

26. Carter SL, Centenera MM, Tilley WD, Selth LA, Butler LM: IkappaBalpha mediates prostate cancer cell death induced by combinatorial targeting of the androgen receptor. BMC cancer 2016, 16:141.

\section{Figures}
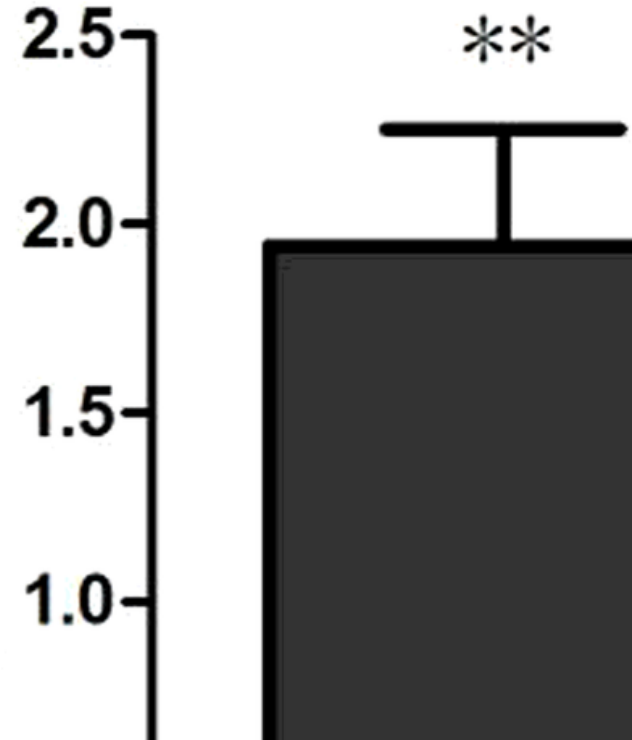

$0.5-$
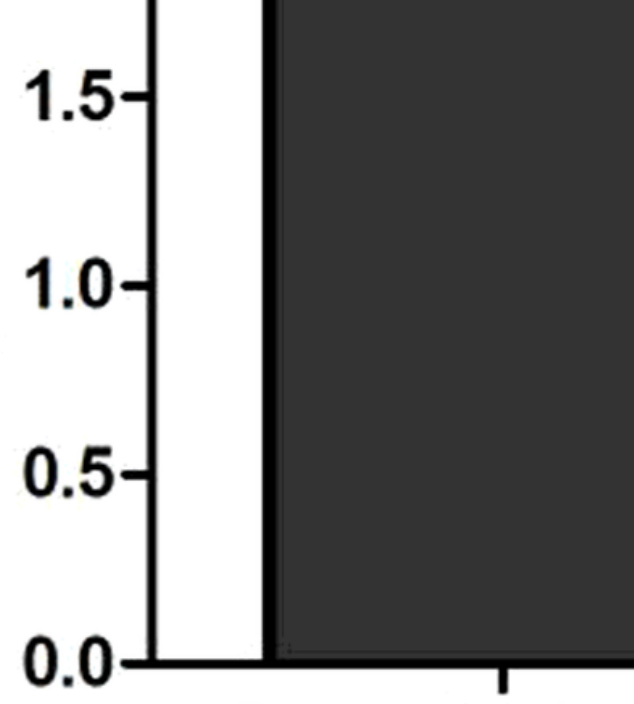
The mRNA expression of NFKBIA in serum samples of prostate cancer patients and healthy controls. The relative expression level of NFKBIA in prostate cancer patients was higher than in the healthy specimens $(\star \star, P<0.01)$.

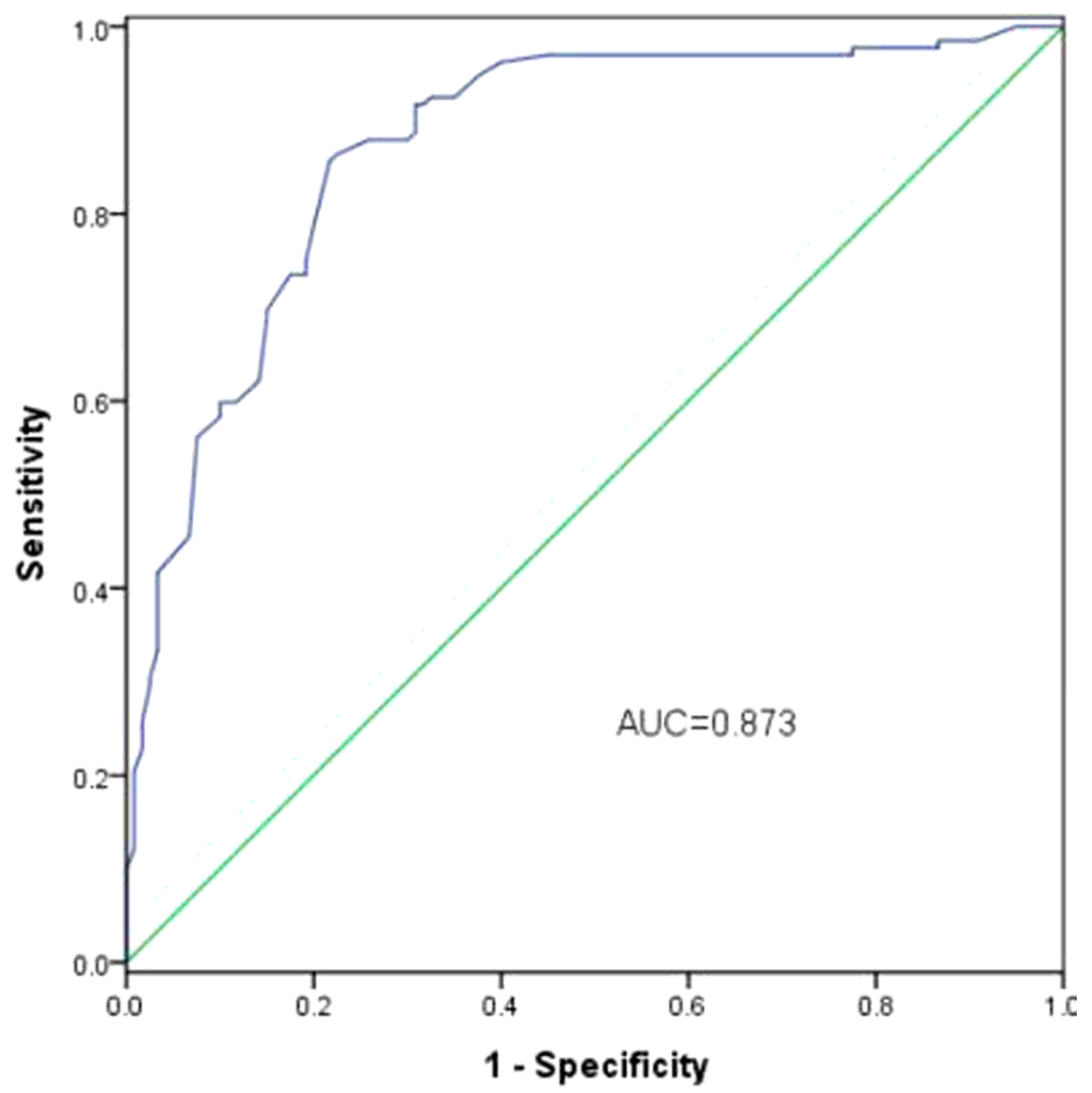

Figure 2

ROC curve analysis for the diagnostic significance of NFKBIA in prostate cancer patients. 